\title{
A broader phenotype of persistence emerges from individual differences in response to extinction
}

\author{
Bruno Sauce $^{1} \cdot$ Christopher Wass $^{1} \cdot$ Michael Lewis $^{1} \cdot{\text { Louis D. } \text { Matzel }^{1}}^{1}$
}

Published online: 13 November 2017

(C) Psychonomic Society, Inc. 2017

\begin{abstract}
The typical practice of averaging group performance during extinction gives the impression that responding declines gradually and homogeneously. However, previous studies of extinction in human infants have shown that some individuals persist in responding, whereas others abruptly cease responding. As predicted by theories of control, the infants who quickly resign typically display signs of sadness and despair when the expected reward is omitted. Using genetically diverse mice, here we observed a similar pattern of individual differences and the associated phenotypes. After learning to approach a food reward, upon extinction, some animals rapidly abandoned approach to the goal box, whereas other animals persisted in entering and searching the goal box. Interestingly, the persistent mice were slower to "give up" when confined to an inescapable pool of water (a test asserted to be indicative of susceptibility to depression) and exhibited a more extensive pattern of search for omitted rewards. Thus, extinction reveals a continuum in persistence, in which low values might reflect a susceptibility to the negative effects of stress and might predispose individuals to depression.
\end{abstract}

Keywords Extinction $\cdot$ Mouse $\cdot$ Persistence $\cdot$ Individual differences $\cdot$ Depression

The omission of an expected reward is known as "extinction," and this treatment leads to a decrease in goal directed behavior. Extinction curves (which typically illustrate average responses across groups of individuals) can obscure the variance

Louis D. Matzel

matzel@ rci.rutgers.edu

1 Department of Psychology, Program in Behavioral and Systems Neuroscience, Rutgers University, Piscataway, NJ 08854, USA between individuals, giving the impression that extinction is gradual and relatively homogeneous. In fact, extinction can occur at dramatically different rates across individuals (Andrews \& Debus, 1978; Quinn, Brandon, \& Copeland, 1996), and extensive work indicates that emotional responses to shifts in reward (including extinction) are related to dramatic personality differences (Corr, Pickering, \& Gray, 1995; Gray, 1970).

Interestingly, persistence during extinction could be beneficial in many circumstances. A series of studies showed that during extinction, some human infants exhibit persistence accompanied by facial displays of anger (Alessandri, Sullivan, \& Lewis, 1990; Crossman, Sullivan, Hitchcock, \& Lewis, 2009; Sullivan, Lewis, \& Alessandri, 1992), whereas others quickly stop responding and exhibit expressions of sadness (Lewis \& Ramsay, 2005). These distinct individual differences were consistent from four to at least 24 months of age (Lewis, Sullivan, \& Kim, 2015) and suggest the possibility of differences in a broader phenotype. Indeed, work by others suggests that children who express sadness in response to challenging situations often exhibit an absence of control, low self-worth, and a disposition for learned helplessness, all of which are associated with depression (Burhans \& Dweck, 1995; Kistner, Ziegert, Castro, \& Robertson, 2001).

Extinction has received tremendous attention in studies with non-human animals, and a number of studies have also assessed the emotional consequences of extinction, such as frustration from lack of reward, incentive downshifts, and extinction-induced aggression (Durlach, 1986; King, Scott, Graham, \& Richardson, 2017; Matzel, 1984; Papini, 2014). However, little attention has been directed to how individual differences in persistence to extinction might be related to a broader phenotype, and no animal studies have been performed that are analogous to those with human infants described above. This is unfortunate, because individual 
differences in response to extinction may have important implications for such phenomenon as addiction relapse, resilience under stress, and susceptibility to depression.

Here we assessed individual differences in persistence in mice during extinction, and simultaneously monitored other traits that might be co-expressed with these differences such as susceptibility to depression, learning, and stress reactivity. The outbred mouse strain (CD-1) used here exhibit levels of behavioral and genetic variability comparable to wild mice (Aldinger, Sokoloff, Rosenberg, Palmer, \& Millen, 2009), and thus are used extensively in studies of individual differences (Kolata, Light, \& Matzel, 2008; Matzel et al., 2011; Matzel et al., 2006; Wass et al., 2013).

\section{Materials and method}

\section{Subjects}

We used 26 outbred CD-1 male mice (Harlan Sprague Dawley Inc., Indianapolis, IN) that weighed 25-30 g and were approximately six weeks of age upon arrival in our laboratory. Such mice express genetic variability comparable to that of wildtype mice, and have been observed to express a wide degree of behavioral variability. The mice were individually housed in clear shoebox cages inside a temperature-controlled colony room with a $12: 12 \mathrm{~h}$ light-dark cycle. To reduce the effect of individual differences in stress due to interactions with the experimenter, we handled all mice daily for $90 \mathrm{~s}$ during the two weeks before the start of behavioral testing. (Handling consisted of holding a mouse on the palm of an experimenter's hand and systematically carrying it through the laboratory.) This handling is a routine procedure in our studies on individual differences in mice, and it leads to a noticeable reduction in mice's defensive behaviors during tests. The mice were young adults (eight weeks of age; approximately equivalent of an 18year-old human) at the start of testing, and had not participated in any other test before the present study.

\section{Behavioral tests}

We measured the mice's learning and extinction in a long alley. We also tested the same mice for anxiety/general arousal in an open-field test, for spatial learning in a spatial water maze, and for their predisposition to depression using the forced swim test. The timeline for testing is illustrated in Fig. 1. Since we were interested in individual differences, all mice were administered these tests in the same order. Except during testing in the long alley, all of the mice were fed ad libitum.

Persistence during extinction The long alley is a simple task that requires a mouse to traverse a straight alley (from a start box) to a goal box to obtain a piece of food. The time to traverse the alley decreases over successive trials as a hungry mouse learns that food is located in the goal box. The apparatus that we used was made of black Plexiglas and consisted of a long alley (112 cm long, $6.5 \mathrm{~cm}$ wide) with a small starting area $(10 \mathrm{~cm}$ long) delimited by a remotely operated vertical door. The alley ended in another remotely operated vertical door, which led to a large, circular goal area (42 cm in diameter). On the side opposite the entry door, the goal area had a food cup on the Plexiglas floor, formed by a 7-mm diameter, 5-mm deep depression.

For the acclimation to the long alley, we let each mouse freely explore the alley and goal box with doors opened and food absent for $12 \mathrm{~min}$. For acquisition training, in each trial we placed a mouse in the start box for $20 \mathrm{~s}$. Then all doors were opened, and the mouse was allowed to run freely toward the goal area, which had the food cup on the floor baited with a piece of food (14-mg Noyes rodent grain pellet). When the mouse reached the goal area, the doors were closed, and the mouse was confined there for $60 \mathrm{~s}$. We administered ten days of acquisition training with six trials per day. From our previous experience, this level of training is sufficient to support a high level of efficacy and super-asymptotic performance (indicated by a reduction in running speed) in all mice. After the completion of acquisition, we started the extinction phase of training, which lasted for two days, with six trials each day. The first two trials of the first day were exactly the same as those during the acquisition phase (i.e., they served as two additional acquisition training trials). For the next ten trials, food was absent from the food cup. Ten days after completion of the extinction training, we tested the mice's reacquisition of the learned response to obtain food. During this reacquisition phase, mice received trials identical to those during the initial acquisition phase. In all phases, we food-deprived the mice by giving them only $90 \mathrm{~min}$ of access to food daily (delivered near the end of the mice's light cycle), beginning on the day prior to training. This protocol leads to an average loss of $5 \%$ of the animals' ad libitum body weight, which is a mild level of deprivation relative to those in many studies. During all phases, we measured the time (from the opening of the doors) for a mouse to reach the goal area. During the extinction phase, more persistent mice should traverse the alley faster than mice that more quickly abandon the previously learned running response.

Anxiety or general arousal The open field is a commonly used test of the propensity for anxiety and/or stress reactivity, in which mice are allowed to explore a novel, typically stressinducing, open space (for a review of the topic, see Prut $\&$ Belzung, 2003). In a walled open field, rodents typically spend a majority of their time around the periphery of the field and avoid entering the center (unwalled) areas. Here we used a $46 \times 46 \mathrm{~cm}$ box with 20 -cm high walls of white Plexiglas as the open field. The floor of the box was divided by tape, creating a grid pattern dividing the space into squares next to the outer walls of the field (i.e., "walled squares") and squares 


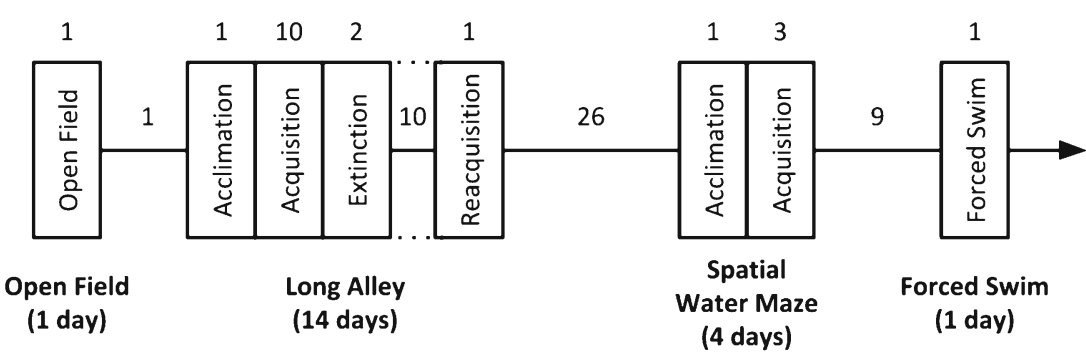

Fig. 1 Timeline of the tests for a single run of mice: open field, long alley, spatial water maze, and forced swim. Numbers indicate the duration of each test, in days. Space between the rectangles indicates resting time, with no experimental manipulations

in the interior of the field (i.e., "center squares"). The box was located in a brightly lit room in order to make the center squares even less appealing to explore, since mice are averse of both open spaces and bright lights. We placed the mice in the center of the box and allowed them to explore it for $5 \mathrm{~min}$, while recording for later scoring. As the measure of anxiety, we used the relative time (as a percentage) spent in the walled squares. Thus, higher values indicate a preference for the walled periphery of the field and suggest that the mouse found the center of the field anxiety- or stress-provoking.

Spatial learning The spatial water maze requires mice to locate a submerged platform in a pool of opaque water from which they are motivated to escape. With no explicit intramaze cues, mice's performance in this maze is highly dependent on spatial cues located outside the pool (Morris, 1981). The path length to locate the platform typically decreases over successive trials, despite entering the pool from different locations at each trial. The present apparatus consisted of a circular pool (diameter: $121 \mathrm{~cm}$, depth: 42 $\mathrm{cm}$ ) filled with water made opaque by nontoxic black paint. A black platform (10 $\mathrm{cm}$ in diameter) was hidden, submerged $3 \mathrm{~cm}$ under the water. The pool was placed inside a dark room and surrounded by a black curtain, with three bright but differently shaped patterns of lights that served as the visual cues.

For the acclimation to the pool, we confined each mouse to the pool's platform (which was surrounded with a clear Plexiglas cylinder) for $4 \mathrm{~min}$. For the acquisition phase, on each trial the mice were started from a different position by the wall (out of three possible positions). The platform was always in the same position. A mouse was said to have successfully located the platform when it remained on the platform for $5 \mathrm{~s}$. After a mouse had located the platform or swum for $90 \mathrm{~s}$, we left or placed the mouse on the platform for $5 \mathrm{~s}$, after which we removed it for a 10-min intertrial interval inside a warmed holding box. Each mouse completed three days of training, with seven trials per day, and was recorded for later scoring. We used the path length covered by each mouse inside the pool as the measure of spatial learning.

Forced swim test (susceptibility to depression) The forced swim test is commonly used to assess the propensity for depression in rodents. This test is based on the principle that some individuals stop swimming (become immobile) when confined in an inescapable tank of water. The test has good predictive validity, since the majority of clinically used antidepressants decrease the duration of immobility (for a review of the topic, see Porsolt, Brossard, Hautbois, \& Roux, 2001). We placed the mice individually in a vertical plastic cylinder containing water at $20{ }^{\circ} \mathrm{C}$ (with a $24{ }^{\circ} \mathrm{C}$ air temperature) that was $30 \mathrm{~cm}$ in diameter $\times 40 \mathrm{~cm}$ deep, for $6 \mathrm{~min}$. During this time, we measured the total duration of immobility, defined as the time a mouse floated passively in the water with no other movement beyond the occasional alternate movements of paws and tail necessary to keep head/nose above water. A higher duration of immobility correlates with a higher tendency toward depression (as the mouse "gives up" fighting for survival) and is indicative of higher sensitivity to treatments that induce depression-like symptoms (PetitDemouliere, Chenu, \& Bourin, 2005).

\section{Serum levels of corticosterone during stress}

One day after the end of the behavioral tests, we measured the mice's levels of corticosterone, an important stress hormone. First, to maximize individual differences in physiological stress response, we placed the mice in a $50-\mathrm{mL}$ Eppendorf tube for 10 min under a bright source of light (a procedure described as "restraint" stress). We then collected trunk blood by decapitation and allowed it to clot. The blood was centrifuged, and aliquots of serum were stored at $-80{ }^{\circ} \mathrm{C}$ until analyzed. We used a commercially available enzyme immunoassay kit (Arbor Assays, K014-H1), following the manufacturers' procedures to determine serum levels of corticosterone.

\section{Statistical analyses}

We defined the individual differences in persistence on the basis of the last two trials of the extinction phase in the long alley (where the highest variance in persistence was observed; 
see below). We then performed two different types of analyses:

1. Linear regression analyses, with individual differences in persistence as the predictor of anxiety/general arousal (open field), spatial learning (spatial water maze), susceptibility to depression (forced swim), and stress response (serum levels of corticosterone after stress). These analyses included all mice in this study.

2. Two-tailed $t$ tests and analyses of variance (ANOVAs), to compare the groups at the two extreme ends of persistence.

These groups consisted of the top 20\% $(n=5)$ and the bottom $20 \%(n=5)$ of mice in terms of persistence. We based these thresholds on the same percentages of top $20 \%$ and bottom $20 \%$ used in the human studies described above, because setting this standard would make future comparisons between species easier. We contrasted these two groups of mice on their performance in spatial learning (spatial water maze), susceptibility to depression (forced swim), and levels of stress response (serum levels of corticosterone after stress).

We also performed repeated measures ANOVAs, correlations, and power analyses, as described below. We used SPSS 21 for all analyses. The data in figures and text are expressed as mean and standard error of the mean. We considered a $p$ value below .05 to indicate significance.

\section{Results}

\section{Long alley and persistence during extinction}

For the long alley, we describe performance during the initial phase of acquisition, during extinction, and during reacquisition. As can be seen in Fig. 2a, the mice, on average, exhibited a fast decline in the latency to reach the goal box. By the end of training (Trial 62; 60 trials during acquisition phase and 2 refresher trials during extinction phase), there was very little variation in latencies across mice, which suggests that all mice learned the basic pattern quickly and to comparable degrees. During extinction (Trials 63-72), the average latency to reach the goal increased substantially. Note also the large increase in variability observed during extinction, in which a mixedmodel analysis showed that $38 \%$ of the variance in performance at the end of extinction was explained by individual differences alone. During reacquisition (starting ten days after the completion of extinction training; Trials 73-78), latencies again decreased, ultimately reaching their preextinction values. Notably, mice reached asymptotic levels of performance with far less training after extinction than in the initial acquisition - that is, they exhibited facilitated reacquisition.
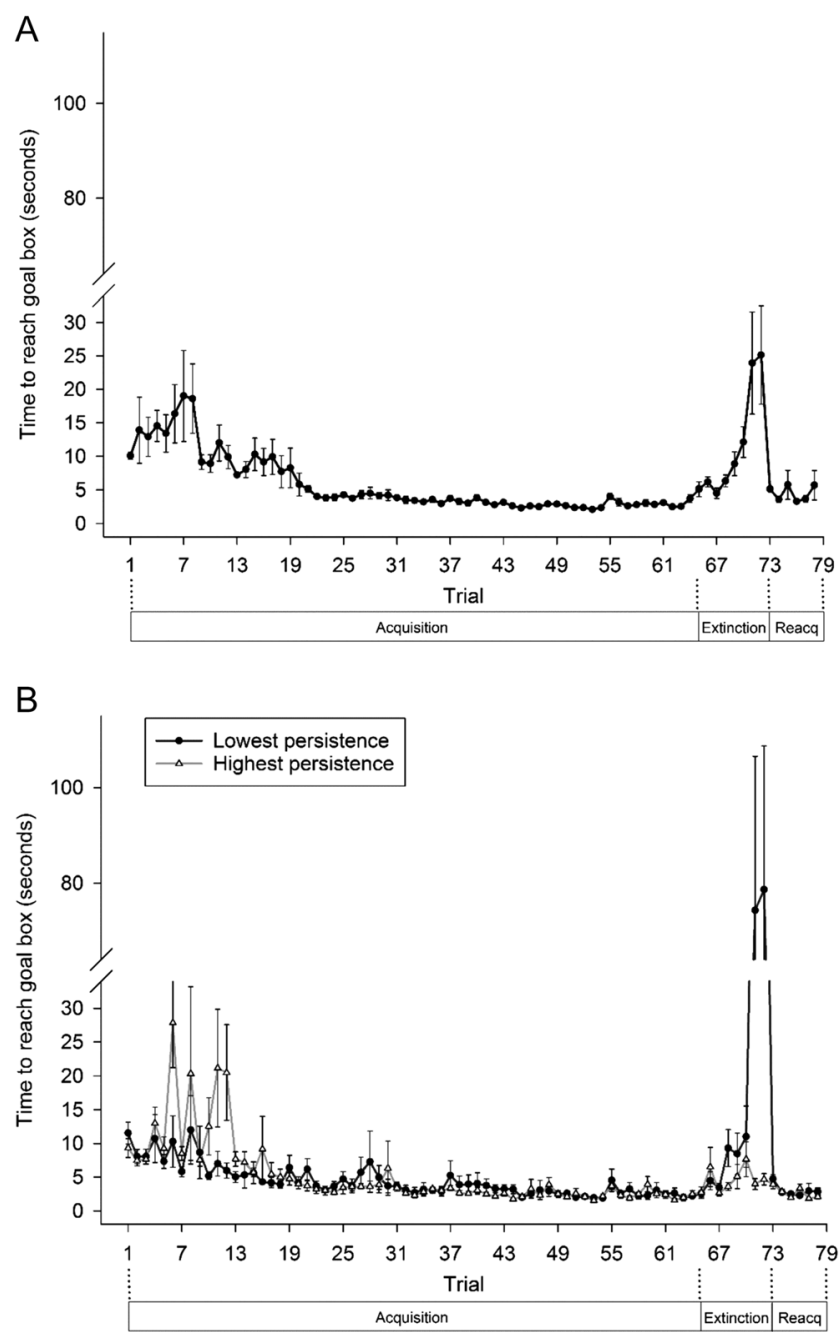

Fig. 2 a Average times, in seconds, for all mice to reach the goal box during initial acquisition, extinction, and reacquisition. b Average times, in seconds, for the five least persistent and the five most persistent mice identified during extinction. Brackets indicate standard errors of the means

Figure $2 b$ illustrates the performance of the five mice that were most or were least persistent during extinction across all phases of training. Regarding the acquisition phase, we used Trials 1-24 (the approximate trial on which the mice were approaching asymptote) as a measure of their rate of learning. There were no differences in learning between the five least persistent mice and the five most persistent mice, $F(1,7)=$ $2.75, p=.141, \eta_{\mathrm{p}}^{2}=.28$. As expected, at the end of the acquisition phase (Trials 59-60), the two groups had similar latencies to reach the goal, $t(8)=0.71, p>.250$, with an effect size of $d=0.45$. By the last two of the ten extinction trials (Trials 71-72), the time to reach the goal was significantly different between the five least persistent and the five most persistent mice, $t(8)=3.44, p=.009$, with an effect size of $d=$ 2.17. Note that whereas the most persistent mice exhibited no appreciable change in behavior during extinction, the least persistent mice exhibited rapid and complete extinction. In 
fact, by the end of extinction training, the least persistent mice were running slower than on the initial acquisition trials, $t(4)=$ $3.25, p=.031$. By the end of reacquisition (last two trials), these two populations were again performing similarly, exhibiting no differences in running speed and performing at a level comparable to that at the end of initial acquisition, $t(7)=1.27, p=.246, d=0.80$.

During extinction training, we recorded the distance traveled in the circular goal box after a mouse had encountered the empty food cup. Exploration of the goal box during an extinction trial might be regarded as an active search for the missing reward, and thus might serve as an independent measure of persistence. Although the extreme groups of the most and least persistent mice did not differ on this measure, the distance traveled was significantly predicted by levels of persistence across all mice in the study, $\beta=-.45, t(25)=2.52, p=.018$.

\section{Anxiety/general arousal}

The results for the open field are illustrated in Fig. 3. Across all mice in the study, the relative time spent in the periphery (walled squares) was not significantly predicted by persistence, $\beta=.23, t(25)=1.20, p=.241$. Also, the five most persistent mice did not differ significantly from the five least persistent mice, $t(8)=0.04, p>.250$, with a very small effect size, $d=0.03$.

\section{Spatial learning}

The results for the spatial water maze are illustrated in Fig. 4. We used the mean distance traveled (path length) by each mouse from Trials 2 to 6 as a measure of the rate of spatial learning. These trials seem to be a good indicator of the differences in rates of acquisition, and we have used them elsewhere for this purpose (Kolata, Wu, Light, Schachner, \& Matzel, 2008; Sauce et al., 2015). As expected, we found that, across all mice, the rate of learning was not significantly predicted by persistence in the long alley, $\beta=.29, t(22)=1.421$, $p>.250, R^{2}=.08$. Furthermore, the rates of learning were not significantly different between the five most persistent and the five least persistent mice, $t(8)=0.44, p>.250, d=0.28$. At the end of the spatial water maze, the five least persistent mice seemed to travel the same distance as the five most persistent ones. Together with the results from the long alley, these data provide further evidence that differences in persistence during extinction are not a reflection of differences in learning.

\section{Forced swim test (susceptibility to depression)}

The results for the forced swim are illustrated in Fig. 5. Across all mice in the study, the duration of immobility was significantly predicted by persistence in the long alley, $\beta=.46, t(22)$ $=2.45, p=.023$, such that the mice that were more persistent

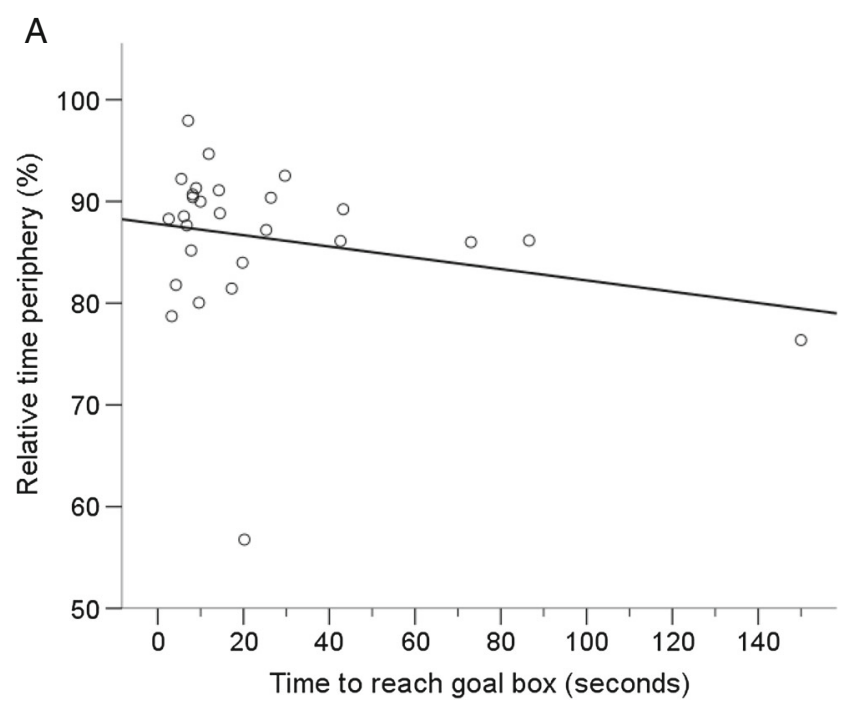

B

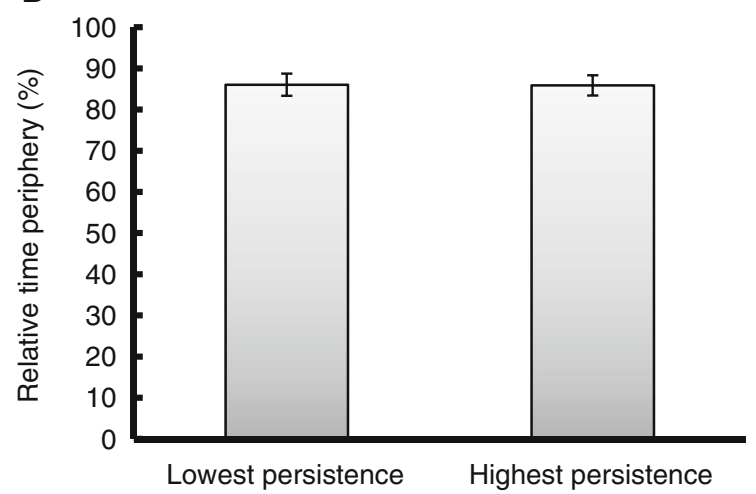

Fig. 3 a Individual values for all mice of time to reach the goal box (in seconds) in the long alley versus time spent in the periphery (as a percentage) in the open field. The linear regression was not significant. b Mean relative times spent in the periphery (as percentages) of the open field for the five least persistent and the five most persistent mice. There was no significant difference between the two groups

during extinction also exhibited more persistent swimming; that is, they were less likely to become passive. The regression model explained $21 \%$ of the total variance in immobility, $R^{2}=$ $.21, F(1,22)=6.00, p=.023$. In the contrast of only the two extreme groups, the five most persistent mice during extinction exhibited significantly more mobility than did the least persistent mice, $t(8)=2.58, p=.033$, with a large effect size, $d=1.82$ (see Fig. $5 \mathrm{~b}$ ).

\section{Serum corticosterone levels during stress}

Across all mice in the study, the corticosterone response to a stressful situation (forced restraint) was not significantly predicted by persistence during extinction in the long alley, $\beta=-.02$, $t(22)=0.07, p>.250$. In the group comparison of the extreme groups, the five most persistent mice also did not differ significantly from the five least persistent mice, $t(8)=0.40, p>.250$, with a small effect size, $d=0.28$ (see Fig. 6b). 

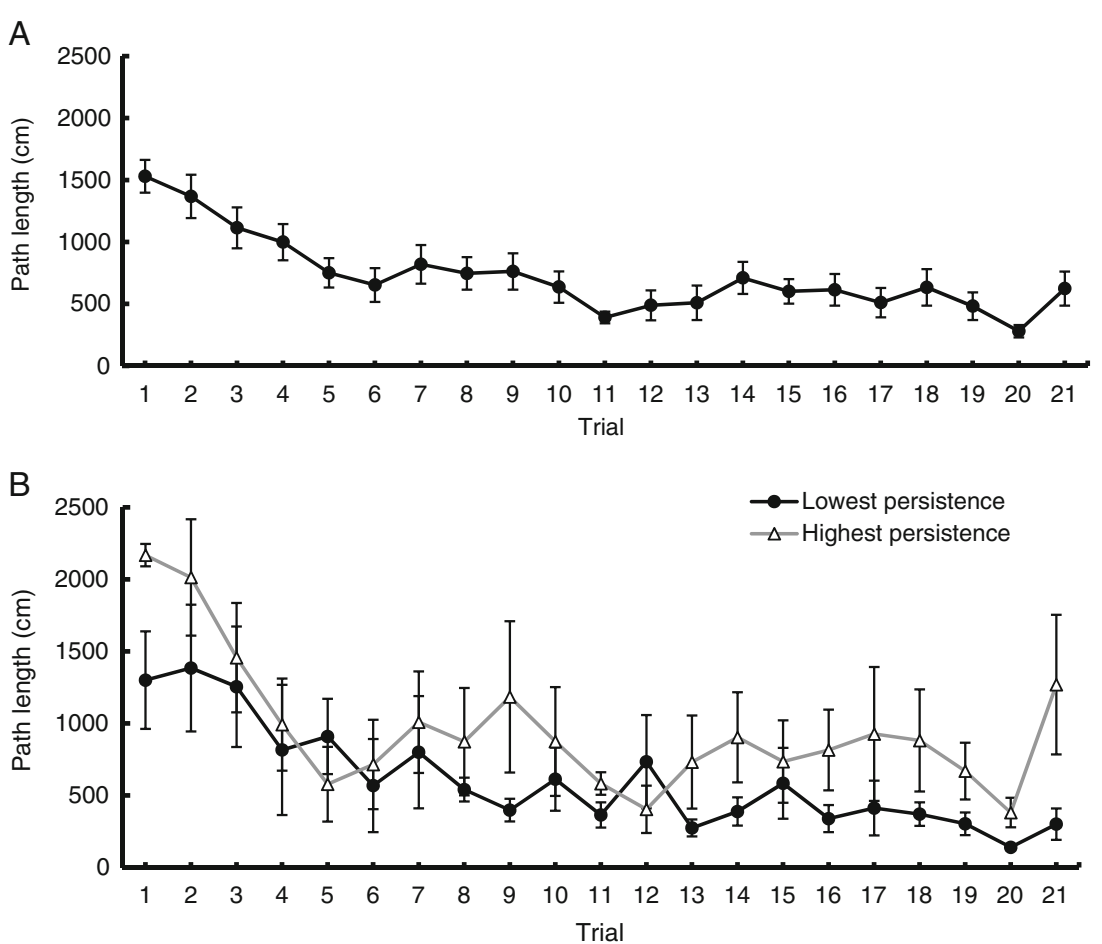

Fig. 4 a Average distances traveled (path length, in centimeters) in the water maze for all mice. $\mathbf{b}$ The five least persistent and the five most persistent mice during extinction in the straight alley were compared across 21 trials in the water maze. There were no significant differences in the rates of learning or in asymptotic performance between the two groups. Brackets indicate standard errors of the means

\section{Discussion}

Extinction "curves" based on averages support the impression that individuals exhibit a slow and gradual decline in goal-directed behavior after the removal of reward. Here, genetically heterogeneous mice differed dramatically in their persistence of response during extinction. Some quickly suppressed responding, whereas others exhibited very high persistence. These mice also presented other patterns of behavior that covaried with persistence, and the extremes of the continuum were quite different in the key phenotypes.

These differences in response to extinction did not seem to be a product of differences in the rates at which the mice learned. Mice that were more persistent during extinction were not better at new learning of either spatial navigation or the long-alley task. Hence, individual differences in extinction might reflect differences in emotionality, as has been found in human infants (Lewis \& Ramsay, 2005). Similarly, there is a possibility that factors such as general arousal or temperament might play a role in the rate at which an individual extinguishes goal-directed responding. Our results with the open field here, however, suggest that this may not be the case. Mice's behavior in the open field can usually reveal differences in emotionality or anxiety, but our persistent mice did not differ from the nonpersistent ones in their patterns of behavior in the open field.
A positive correlation was observed between mice's level of persistence during extinction and the amount of search behavior engaged in after encountering the empty food cup. Moreover, mice that were more persistent during extinction continued swimming in a pool of inescapable water after the low-persistence mice had "given up" (i.e., resorted to passive floating). The forced swim test is considered a reliable predictor of the susceptibility to depression in mice and is a common screening method for the efficacy of putative antidepressant drugs (Petit-Demouliere et al., 2005). Thus, the phenotype that emerges in response to extinction may be indicative of susceptibility to some forms of depression. Our results with mice are remarkably similar to the observation that human infants who rapidly suppress responding during extinction display sadness and despair when the expected reward is withheld (Kistner et al., 2001; but see Cloninger, Zohar, Hirschmann, \& Dahan, 2012), and persistence training may inoculate individuals against depression (Nation \& Massad, 1978). It is important to note that our study only used male animals, and so our conclusions on persistence and its broader phenotype are sex specific. This may be particularly relevant regarding predisposition to depression, the etiology of which is probably different in males and females.

Here, persistence was unrelated to glucocorticoid levels in response to environmental stress. This contrasts with results obtained in children, in which those who rapidly abandon 
A

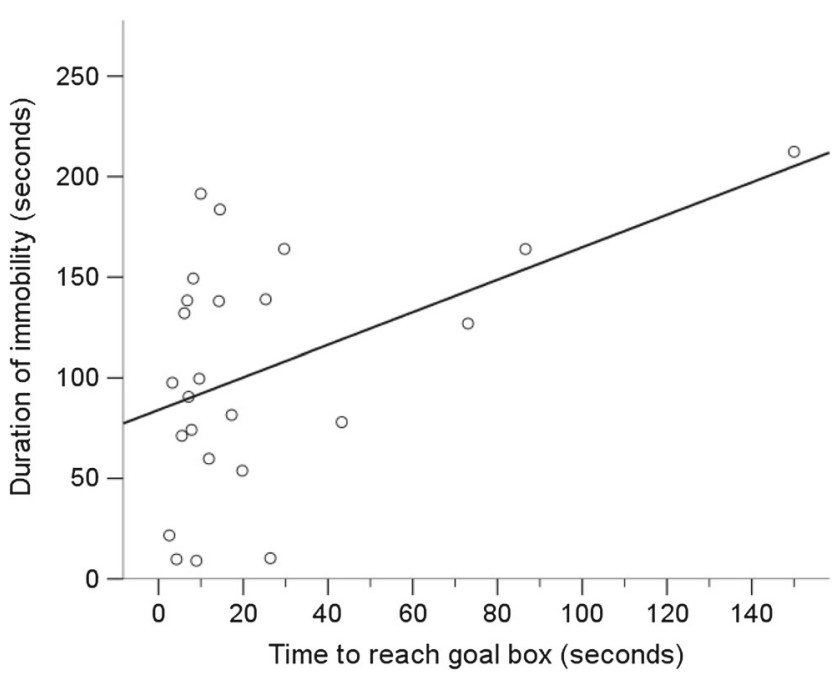

B

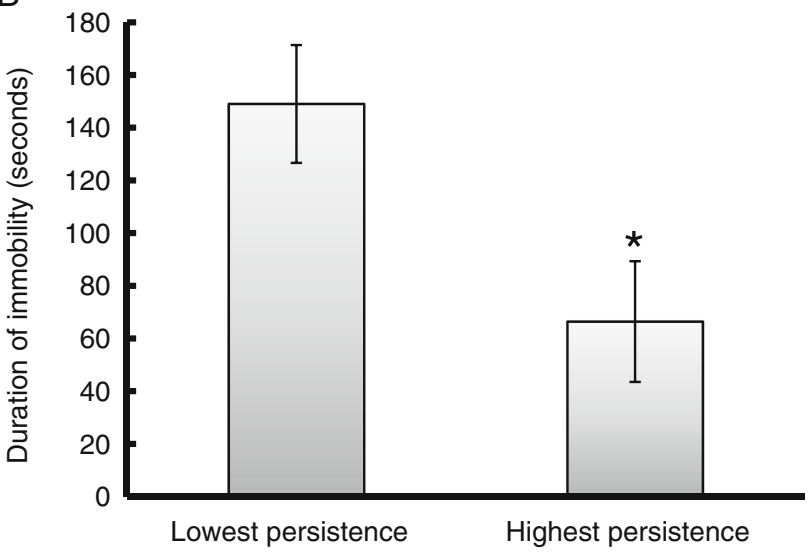

Fig. 5 a Individual values for all mice of time to reach the goal box (in seconds) in the long alley versus the duration of immobility (in seconds) during the forced swim. The linear regression was significant. b Mean durations of immobility (in seconds) during the forced swim for the five least persistent and the five most persistent mice (during extinction in the long alley). ${ }^{*} p<.05$. Brackets indicate standard errors of the means

responding during extinction exhibit sadness and higher levels of cortisol after a stressor (Lewis \& Ramsay, 2005). Relatedly, the high- and low-persistence mice tested here did not differ in their patterns of behavior in an open field, a test that can be sensitive to differences in anxiety or stress reactivity. Thus, it does not appear that persistence need necessarily be related to differences in stress reactivity, but instead may emerge independently.

An alternative explanation to the one we have put forward here is that the positive correlation between persistence and forced swim is not indicative of persistence per se, but of an underlying physiological trait, such as vigor, or a motivational state. However, we believe this is unlikely to be the case, since behavior in the open field (which is sensitive to general arousal) was unrelated to persistence. Moreover, a motivational state is likely to impact acquisition and/or asymptotic
A

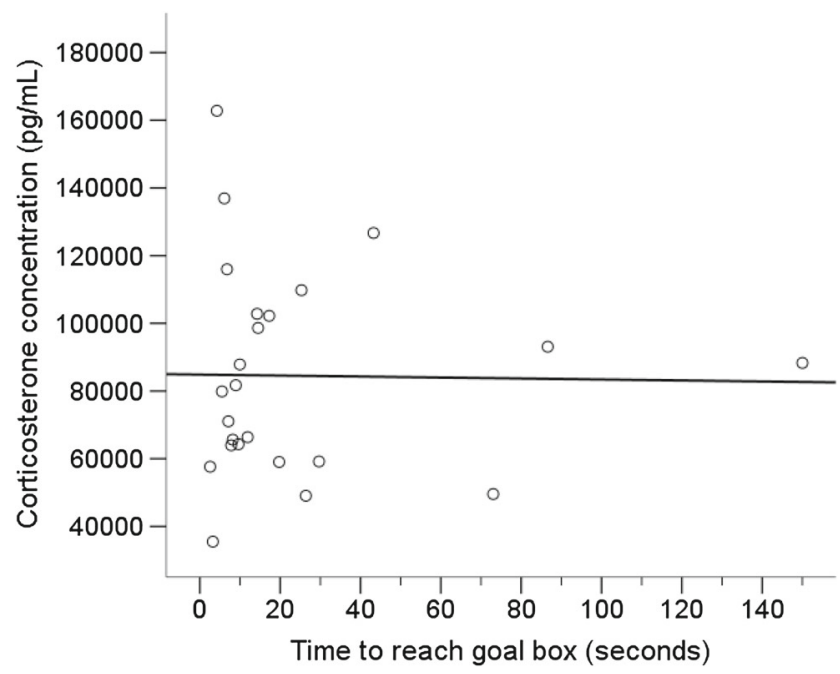

B

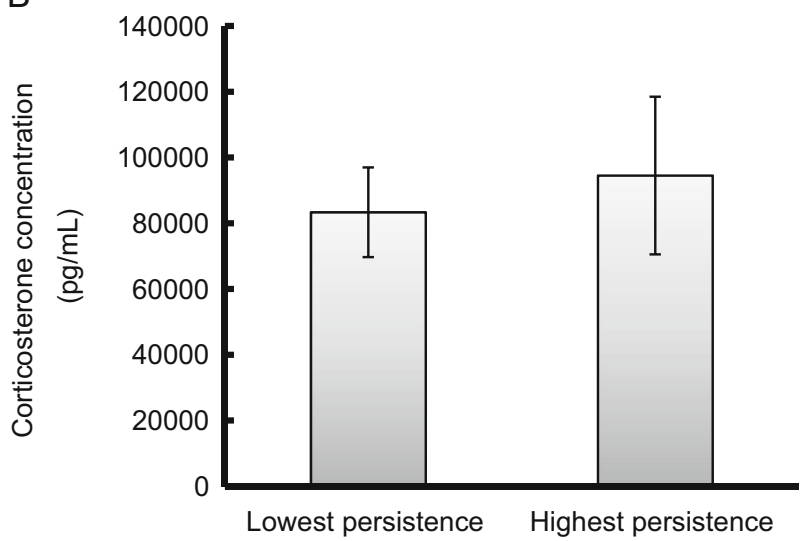

Fig. 6 a Individual values for all mice of time to reach the goal box (in seconds) in the long alley versus serum corticosterone concentration after an acute stress. The linear regression was not significant. b Mean serum corticosterone concentrations after acute stress for the five least persistent and the five most persistent mice. There were no significant differences between the two groups

performance during learning, and in the present experiment no relationship between learning and persistence was observed. In total, the present results suggest that differences in persistence emerge independently of motivation or arousal.

The present results suggest that the continuum in persistence revealed in response to extinction reflect broader phenotypic differences. Furthermore, a persistent phenotype might be protective and lead to more resilience. Some humans exposed to stressful events never exhibit such psychopathology as posttraumatic stress disorder or depression (Yehuda, 2004). These "resilient" individuals display traits such as cognitive flexibility and optimism (Charney, 2004). This can be further elucidated in mice through environmental manipulations. For instance, exposure to novel environments promotes increases in exploratory behaviors (Franks, Champagne, \& Higgins, 2013; Light, Kolata, Hale, Grossman, \& Matzel, 
2008) and might transform mice that "give up" into persistent ones. Such studies could aid our understanding of the interplay of extinction, persistence, control, and depression in humans. Furthermore, persistence as revealed by extinction might provide insights into individual sensitivities to antidepressant drugs, which are often effective in only a small percentage of recipients (Kirsch, 2008).

Author note This work was supported by grants from the National Institute of Mental Health (AG022698) and the Office of Naval Research (MH108706) to L.D.M.

\section{References}

Aldinger, K. A., Sokoloff, G., Rosenberg, D. M., Palmer, A. A., \& Millen, K. J. (2009). Genetic variation and population substructure in outbred CD-1 mice: Implications for genome-wide association studies. PloS One, 4, e4729. https://doi.org/10.1371/journal.pone.0004729

Alessandri, S. M., Sullivan, M. W., \& Lewis, M. (1990). Violation of expectancy and frustration in early infancy. Developmental Psychology, 26, 738-744. https://doi.org/10.1037/0012-1649.26.5.738

Andrews, G. R., \& Debus, R. L. (1978). Persistence and the causal perception of failure: Modifying cognitive attributions. Journal of Educational Psychology, 70, 154-166. https://doi.org/10.1037/ 0022-0663.70.2.154

Burhans, K. K., \& Dweck, C. S. (1995). Helplessness in early childhood: The role of contingent worth. Child Development, 66, 1719. https://doi.org/10.2307/1131906

Charney, D. S. (2004). Psychobiological mechanisms of resilience and vulnerability. Focus, 2, 368-391. https://doi.org/10.1176/foc.2.3.368

Cloninger, C. R., Zohar, A. H., Hirschmann, S., \& Dahan, D. (2012). The psychological costs and benefits of being highly persistent: Personality profiles distinguish mood disorders from anxiety disorders. Journal of Affective Disorders, 136, 758-766. https://doi.org/10.1016/j.jad.2011.09.046

Corr, P. J., Pickering, A. D., \& Gray, J. A. (1995). Personality and reinforcement in associative and instrumental learning. Personality and Individual Differences, 19, 47-71. https://doi.org/10.1016/01918869(95)00013-V

Crossman, A. M., Sullivan, M. W., Hitchcock, D. M., \& Lewis, M. (2009). When frustration is repeated: Behavioral and emotion responses during extinction over time. Emotion, 9, 92-100. https://doi.org/10.1037/a0014614

Durlach, P. J. (1986). Explicitly unpaired procedure as a response elimination technique in autoshaping. Journal of Experimental Psychology: Animal Behavior Processes, 12, 172-185. https://doi.org/10.1037/0097-7403.12.2.172

Franks, B., Champagne, F. A., \& Higgins, E. T. (2013). How enrichment affects exploration trade-offs in rats: implications for welfare and well-being. PLOS ONE, 8, e83578. https://doi.org/10.1371/journal. pone. 0083578

Gray, J. A. (1970). The psychophysiological basis of introversion-extraversion. Behaviour Research and Therapy, 8, 249-266. https://doi.org/10.1016/0005-7967(70)90069-0

King, G., Scott, E., Graham, B. M., \& Richardson, R. (2017). Individual differences in fear extinction and anxiety-like behavior. Learning and Memory, 24, 182-190. https://doi.org/10.1101/lm.045021.117

Kirsch, I. (2008). Antidepressant drugs "work," but they are not clinically effective. British Journal of Hospital Medicine, 69, 359-359. https://doi.org/10.12968/hmed.2008.69.6.29632
Kistner, J. A., Ziegert, D. I., Castro, R., \& Robertson, B. (2001). Helplessness in early childhood: Prediction of symptoms associated with depression and negative self-worth. Merrill-Palmer Quarterly, 47, 336-354. https://doi.org/10.1353/mpq.2001.0016

Kolata, S., Wu, J., Light, K., Schachner, M., \& Matzel, L. D. (2008). Impaired working memory duration but normal learning abilities found in mice that are conditionally deficient in the close homolog of L1. Journal of Neuroscience, 28, 13505-13510. https://doi.org/10.1016/j.intell.2007.12.001

Kolata, S., Light, K., \& Matzel, L. D. (2008). Domain-specific and domain-general learning factors are expressed in genetically heterogeneous CD-1 mice. Intelligence, 36, 619-629. https://doi.org/10.1523/JNEUROSCI.2127-08.2008

Lewis, M., \& Ramsay, D. (2005). Infant emotional and cortisol responses to goal blockage. Child Development, 76, 518-530. https://doi.org/ 10.1111/j.1467-8624.2005.00860.x

Lewis, M., Sullivan, M. W., \& Kim, H. M.-S. (2015). Infant approach and withdrawal in response to a goal blockage: Its antecedent causes and its effect on toddler persistence. Developmental Psychology, 51, 1553-63. https://doi.org/10.1037/dev0000043

Light, K., Kolata, S., Hale, G., Grossman, H., \& Matzel, L. D. (2008). Up-regulation of exploratory tendencies does not enhance general learning abilities in juvenile or young-adult outbred mice. Neurobiology of Learning and Memory, 90, 317-29. https://doi.org/10.1016/j.nlm.2008.04.007

Matzel, L. D. (1984). Aggression in rats as a function of target location in a double alley. American Journal of Psychology, 97, 519-526.

Matzel, L. D., Light, K., Wass, C., Colas-Zelin, D., Denman-Brice, A., Waddel, A. C., \& Kolata, S. (2011). Longitudinal attentional engagement rescues mice from age-related cognitive declines and cognitive inflexibility. Learning and Memory, 18, 345-56. https://doi.org/10.1101/lm.2034711

Matzel, L. D., Townsend, D. A., Grossman, H., Han, Y. R., Hale, G., Zappulla, M., . . . Kolata, S. (2006). Exploration in outbred mice covaries with general learning abilities irrespective of stress reactivity, emotionality, and physical attributes. Neurobiology of Learning and Memory, 86, 228-40. https://doi.org/10.1016/j.nlm.2006.03.004

Morris, R. G. M. (1981). Spatial localization does not require the presence of local cues. Learning and Motivation, 12, 239-260. https://doi.org/10.1016/0023-9690(81)90020-5

Nation, J. R., \& Massad, P. (1978). Persistence training: A partial reinforcement procedure for reversing learned helplessness and depression. Journal of Experimental Psychology: General, 107, 436-451. https://doi.org/10.1037/0096-3445.107.4.436

Papini, M. R. (2014). Diversity of adjustments to reward downshifts in vertebrates. International Journal of Comparative Psychology, 27, 420-445.

Petit-Demouliere, B., Chenu, F., \& Bourin, M. (2005). Forced swimming test in mice: A review of antidepressant activity. Psychopharmacology, 177, 245-255. https://doi.org/10.1007/ s00213-004-2048-7

Porsolt, R. D., Brossard, G., Hautbois, C., \& Roux, S. (2001). Rodent models of depression: Forced swimming and tail suspension behavioral despair tests in rats and mice. In J. N. Crawley (Ed.), Current protocols in neuroscience (Chap. 8, Unit 8.10A). Hoboken: Wiley. https://doi.org/10.1002/0471142301.ns0810as 14

Prut, L., \& Belzung, C. (2003). The open field as a paradigm to measure the effects of drugs on anxiety-like behaviors: A review. European Journal of Pharmacology, 463, 3-33. https://doi.org/10.1016/ S0014-2999(03)01272-X

Quinn, E. P., Brandon, T. H., \& Copeland, A. L. (1996). Is task persistence related to smoking and substance abuse? The application of learned industriousness theory to addictive behaviors. Experimental and Clinical Psychopharmacology, 4, 186-190. https://doi.org/10. 1037/1064-1297.4.2.186 
Sauce, B., Wass, C., Netrakanti, M., Saylor, J., Schachner, M., \& Matzel, L. D. (2015). Heterozygous L1-deficient mice express an autism-like phenotype. Behavioural Brain Research, 292, 432-442. https://doi.org/10.1016/j.bbr.2015.05.040

Sullivan, M. W., Lewis, M., \& Alessandri, S. M. (1992). Cross-age stability in emotional expressions during learning and extinction. Developmental Psychology, 28, 58-63. https://doi.org/10.1037/ 0012-1649.28.1.58
Wass, C., Pizzo, A., Sauce, B., Kawasumi, Y., Sturzoiu, T., Ree, F., . . Matzel, L. D. (2013). Dopamine D1 sensitivity in the prefrontal cortex predicts general cognitive abilities and is modulated by working memory training. Learning and Memory, 20, 617-627. https://doi.org/10.1101/lm.031971.113

Yehuda, R. (2004). Risk and resilience in posttraumatic stress disorder. Journal of Clinical Psychiatry, 65(Suppl. 1), 29-36. Retrieved from www.ncbi.nlm.nih.gov/pubmed/14728094 